\title{
OBOSEALA PROFESIONALĂ ŞI TIPURILE DE SOLICITARE LA LOCUL DE MUNCĂ
}

\author{
Claudia Bălănean ${ }^{1,2}$, Cezar Bălănean ${ }^{1,3}$ \\ SCM Elit Med ${ }^{1}$, medic specialist medicina muncii ${ }^{2}$, medic specialist chirurg ${ }^{3}$
}

\section{Title: The occupational fatigue and overwork types at the post}

Abstract:

Background. The fatigue is an physiologic phenomenon, released by the overwork of body, yet gradual require which supervene over a long period of time.

Objective. We followed the degree of fatigue based on the clinical and psihological consequence in several professional category with various work conditions and diverse type of demands.

Methods. We considered groups of 100 workers with various characteristics of post, which were observed in our practice of occupational medicine and psychological tested on medical survey on the period 2006-2007. We followed the cardiovascular and visual disorders, bone and joint illness, psychiatric disorders and diabetes, like clinical elements in the relation with professional fatigue, also the variation of distributive and concentrate attention as a psychological mark of fatigue.

Results. Cardiovascular, bone and joint disorders prevail to the workers with physical demand. In condition of work in isolation prevail ocular pathology, followed by cardiovascular, bone and joint disorders. The workers with neurosensorial requirements presented predominant bone and joint symptoms and ocular disorders. Activities with hard and medium effort are followed by bone and joint trouble. Desk work induce a grown percentage of heart diseases, bone and joint diseases and ocular disorders. Attention is most affected in physical works.

Conclusions. There is no parallelism between physical effort carried out and the appearance of heart, psyche or bone and joint manifestations. Gathering the overwork circumstances like inadequate positions, visual and neurosensorial overdo, the stress, represent the determinant factor for professional illness and work related accidents.

Key words: fatigue, workers, occupational medicine, overwork, type of demands.

\section{Rezumat}

Introducere în temă. Oboseala este un fenomen fiziologic declanșat de solicitări excesive ale organismului, dar și de solicitări moderate care survin pe o perioadă mai lungă de timp.

Obiective. Am urmărit evaluarea gradului de oboseală pe baza efectelor clinice și psihologice ale acesteia, în cazul mai multor categorii profesionale cu diverse condiții de muncă și diverse tipuri de solicitare.

Material și metode. Au fost luate în lucru loturi de 100 de lucrători cu diferite caracteristici ale locului de muncă, examinați în cabinetul de medicina muncii și testați psihologic în cadrul controalelor medicale periodice pe perioada 2006-2007. Au fost urmărite tulburările cardiovasculare, tulburările de vedere, boli osteoarticulare, tulburările psihiatrice și diabetul zaharat, ca și elemente clinice în relație cu oboseala profesională precum și variația atenției distributive și concentrate, ca indicator psihologic al oboselii.

Rezultate. Afectările cardiace și osteoarticulare predomină la lucrătorii care depun efort fizic. În munca în condiții de izolare, predomină patologia oculară, urmată de tulburările cardiovasculare și osteoarticulare. Lucrătorii cu solicitare neurosenzorială au prezentat predominant simptome 
osteoarticulare și tulburări oculare. Activităţile cu efort fizic mediu sau mare se însoțesc de afecțiuni osteoarticulare. Munca de birou determină un procent crescut de boli cardiace, osteoarticulare, alături de tulburări oculare. Atenția este cea mai afectată în activitatea predominant fizică.

Concluzii. Nu există un paralelism între efortul fizic depus și apariția manifestărilor cardiace, psihice, osteoarticulare. Cumulul de noxe cum ar fi: poziția nonergonomică, suprasolicitarea vizuală și neurosenzorială, stresul, reprezintă un factor principal de îmbolnăvire profesională și de accidente de muncă.

Cuvinte cheie: oboseala, muncitori, medicina muncii, suprasolicitare, tipuri de solicitare.

\section{Noțiuni de bază}

Oboseala apare în timpul muncii atât în urma activităților fizice, cât și a activităților intelectuale. Instalarea oboselii reprezintă practic semnalul de alarmă și ar trebui să fie urmat de încetarea activității și intrarea în faza de refacere a organismului, pentru a se evita fenomenul de epuizare.

Oboseala patologică apare în urma instalării fenomenului de epuizare și poate avea consecințe grave dacă nu are loc recuperarea organismului prin repaus. Lucrătorul obosit are atenția scăzută, este apatic, somnolent, dezinteresat față de activitatea profesională și depune efort de concentrare pentru continuarea activității.

Oboseala crește numărul de erori în activitate, scade calitatea muncii și crește mult riscul de accidente de muncă.

În procesul muncii există două mari categorii de oboseală: oboseala fizică, musculară și oboseala psihică sau nervoasă.

Oboseala musculară este în general acută, dureroasă și se asociază cu scăderea potenței funcționale a mușchiului respectiv. Apare în cazul eforturilor fizice mari, a gestualităţilor profesionale extreme, sau a lipsei antrenamentului din partea persoanei care execută manopera.

Oboseala psihică diferă ca substrat de oboseala musculară, dar poate implica și efortul fizic; deci nu numai activitățile intelectuale conduc la oboseală psihică, ci și cele motorii, ele necesitând o coordonare nervoasă.

Apariția stării de oboseală generală sau oboseală psihică depinde de mai mulți factori, care pot fi grupați în patru categorii:

-factorii individuali

-factorul utilaj

-caracteristicile mediului de muncă

-caracteristicile sarcinii

Factorii individuali (particularități antropometrice, constituția, temperamentul, starea de sănătate, sexul, conflictele sociale) fac ca fiecare lucrător să reacționeze diferit în fața fenomenului de oboseală.

Factorul utilaj deține un rol important în declanșarea fenomenelor cauzate de oboseală, maşinile moderne obligând lucrătorii să mențină un ritm și o încărcătură de gestualități profesionale repetitive, atenție susținută și precizie în timp. Primele care obosesc sunt mecanismele de coordonare motorie. Automatizarea poate fi și ea periculoasă, prin pierderea cadenței și monotonia gestualității.

Caracteristicile sarcinii și caracteristicile mediului de muncă se completează în generarea factorilor obositori. Durata programului de muncă, organizarea pauzelor, munca în ritm impus, suprasolicitarea în timpul muncii, responsabilitatea crescută, sunt factori care țin de organizarea muncii și au ca posibilă finalitate oboseala profesională. Munca în schimburi alternante interferează cu ritmurile circadiene ale activităților nervoase, secretorii endo- și exocrine, fiind perturbat mecanismul somnveghe. Organizarea nonergonomică a locului de muncă poate obliga la gestualități suplimentare, cu poziții forțate, care se vor solda cu suprasolicitări ale diferitelor organe și sisteme.

Factorii mediului de muncă pot precipita instalarea oboselii. Toxicele de la locul de muncă, zgomotul, vibrațiile în doze exagerate, provoacă boli profesionale, iar la intensităţi moderate, dar 
susținute, participă la instalarea stării de oboseală. Relațiile psihosociale în procesul muncii au o importanță deosebită, relațiile încordate, nesatisfacerea nevoilor materiale, fiind la baza tulburărilor comportamentale datorită fenomenelor de stress, oboseală și nesiguranță [1].

Indiferent care sunt factorii care conduc la instalarea fenomenului de oboseală, aceștia au la bază o cheltuială energetică ridicată în cazul factorilor ce presupun efort fizic, sau un consum energetic scăzut în cazul celor psihologici sau intelectuali. Factorii care conduc la instalarea oboselii sunt ilustrați grafic în figura 1.

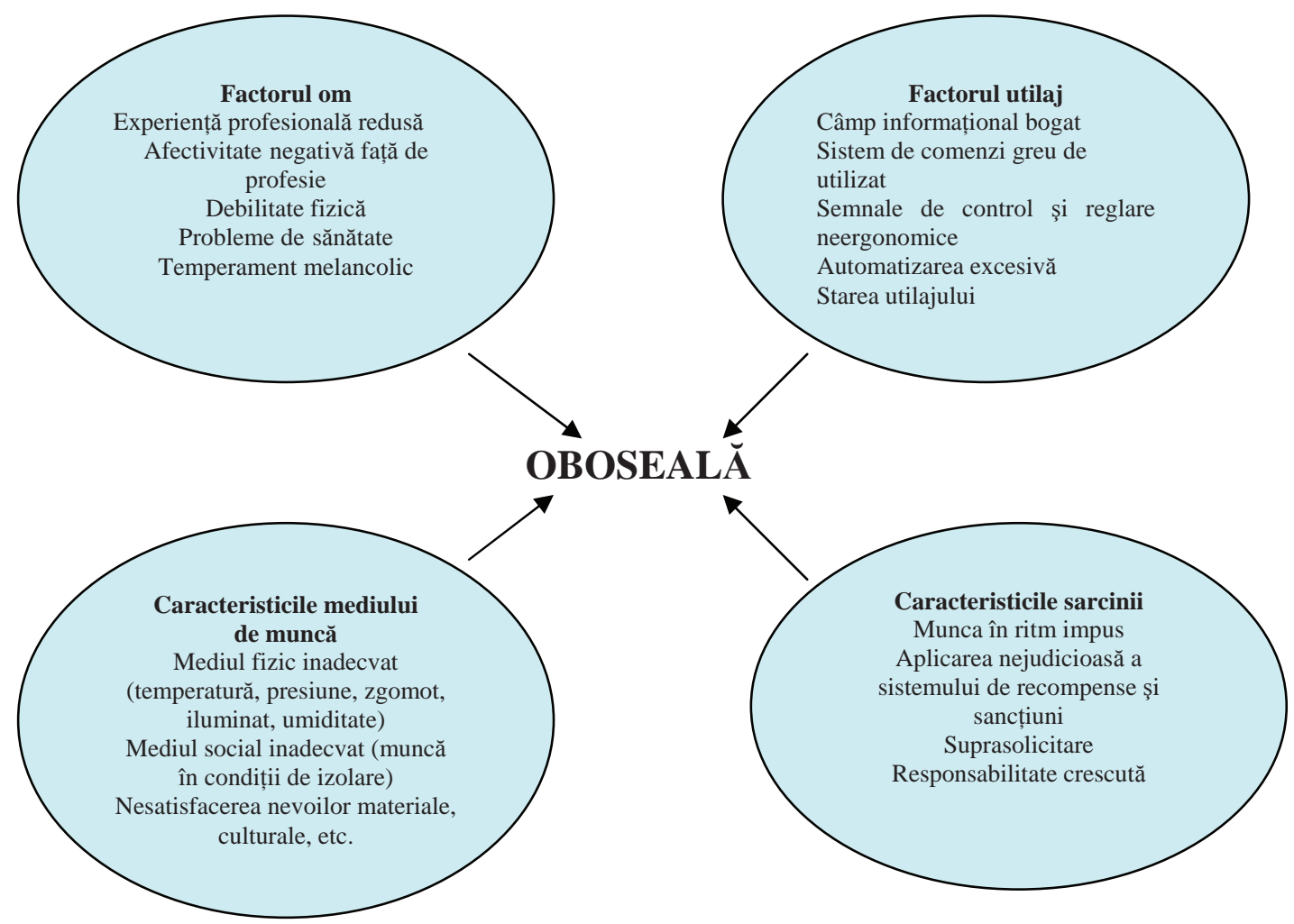

Fig. 1. Factori generatori ai oboselii profesionale, (Bogathy modificată)

Indiferent de tipul de factori care au contribuit la apariția oboselii, există mai multe forme de manifestare a acesteia.

Consecințele fiziologice fac parte din mecanismele adaptative premergătoare statusului de boală: scăderea tonusului, modificări ale pulsului și tensiunii arteriale, scăderea rezistenței organismului la îmbolnăviri.

Consecințele psihologice se traduc prin disconfort psihic, iritabilitate, scăderea funcțiilor cognitive (percepție, memorie, gândire).

Consecințele sociale se datorează iritabilității și agitației și pot fi evidențiate prin conflicte familiale, sau în colectivul de muncă.

Consecințele profesionale constau în scăderea randamentului muncii, creșterea numărului erorilor, risc mărit de a comite accidente de muncă, scăderea motivației și a satisfacției pentru muncă.

Manifestările oboselii pot fi evaluate psihologic printr-o multitudine de probe, care testează în principal performanțele subiecților fie sub forma timpului de reacție, fie a numărului de erori, ori a capacității de decizie [2]. 


\section{Scopul lucrării}

Am urmărit evaluarea gradului de oboseală pe baza efectelor clinice și psihologice ale acesteia în cazul mai multor categorii profesionale cu diverse condiții de muncă și diverse tipuri de solicitare.

\section{Material şi metodă}

Au fost luate în lucru loturi de circa 100 de lucrători, cu următoarele caracteristici ale locului de muncă: -muncă în condiții de izolare 115

-muncă cu solicitare neurosenzorială 108

-activitate cu efort fizic mediu/mare 105

-activitate cu efort fizic mediu, dar expunere la intemperii 110

-muncă de birou 104

-activitate cu efort fizic mic (confecționeri fără expunere la zgomot) 102

-activitate cu efort fizic mic (confecționeri cu expunere la zgomot) 112

Persoanele au fost examinate în Cabinetul de medicina muncii al serviciului nostru din Satu Mare și testate psihologic în cadrul controalelor medicale periodice în perioada 2006-2007.

$\mathrm{Au}$ fost urmărite tulburările cardiovasculare, tulburările de vedere, bolile osteoarticulare, tulburările psihiatrice și diabetul zaharat, ca și elemente clinice în relație cu oboseala profesională precum și variația atenției distributive și concentrate, ca indicator psihologic al oboselii.

\section{Rezultate}

Tulburarile clinice generate de oboseală sau potențial agravate de oboseală la loturile studiate, sunt cuprinse în tabelul I.

Tabelul I. Tulburarile clinice generate de oboseală sau potențial agravate de oboseală

\begin{tabular}{llccccc}
\hline $\begin{array}{l}\text { Nr } \\
\text { crt }\end{array}$ & \multicolumn{1}{c}{ Lot } & $\begin{array}{c}\text { Tulburări } \\
\text { cardiace }\end{array}$ & $\begin{array}{c}\text { Tuburări } \\
\text { de vedere }\end{array}$ & $\begin{array}{c}\text { Boli } \\
\text { osteoarti- } \\
\text { culare }\end{array}$ & $\begin{array}{c}\text { Tulburări } \\
\text { psihiatrice }\end{array}$ & $\begin{array}{c}\text { Diabet } \\
\text { zaharat }\end{array}$ \\
\hline 1 & Muncă în condiții de izolare & 14 & 38 & 12 & 1 & 2 \\
2 & Muncă cu solicitare neurosenzorială & 16 & 36 & 38 & 2 & 3 \\
3 & $\begin{array}{l}\text { Activitate cu efort fizic mediu/mare } \\
4\end{array}$ & 12 & 10 & 31 & 1 & 3 \\
$\begin{array}{l}\text { Activitate cu efort fizic mediu dar } \\
\text { expunere la intemperii }\end{array}$ & 24 & 12 & 35 & 2 & 4 \\
5 & $\begin{array}{l}\text { Muncă de birou } \\
\text { Activitate cu efort fizic mic } \\
6\end{array}$ & 26 & 36 & 36 & 2 & 2 \\
& $\begin{array}{l}\text { (confecționeri fără expunere la } \\
\text { zgomot) }\end{array}$ & 14 & 32 & 24 & 2 & 3 \\
\hline & $\begin{array}{l}\text { activitate cu efort fizic mic } \\
\text { (confecționeri cu expunere la zgomot) }\end{array}$ & 18 & 36 & 26 & 2 & 4 \\
\hline
\end{tabular}

Din datele prezentate se observă o pondere mai mare a afectărilor cardiace și osteoarticulare la lucrătorii care depun efort fizic. La lucrătorii unde solicitarea este predominant vizuală, predomină tulburările vizuale, zgomotul la această categorie augumentând manifestările cardiace.

Munca în condiții de izolare, chiar dacă nu presupune efort fizic, nu este lipsită de elemente patologice. Predomină patologia oculară, în mare parte reprezentată prin vicii de refracție, urmată de tulburările cardiovasculare și osteoarticulare.

Lucrătorii cu solicitare neurosenzorială au prezentat predominant simptome osteoarticulare, lucru care se datorează poziției șezânde prelungite și tulburări oculare.

Activitățile ce presupun efort fizic mediu sau mare necesită uneori și ridicare sau transport de greutăți mari, ceea ce se reflectă în ponderea mare de afecțiuni osteoarticulare. Spre deosebire de 
lucrătorii care își desfăsoară activitatea în hale de producție, cei din domeniul construcțiilor lucrează deseori în condiții extreme de temperatură și umezeală. Acest lucru aduce o creștere a procentului bolilor osteoarticulare și cardiace.

Munca de birou este deseori catalogată ca fiind cea mai comodă și fără noxe. Acuzele legate de starea de sănătate dovedesc contrariul, în rândul acestor lucrători semnalându-se un procent crescut de boli cardiace, osteoarticulare, alături de tulburările oculare la care ne așteptam.

Repartiția patologiei pe loturile studiate este ilustrată în figura 2.

\section{Distribuția patologiei pe loturile studiate}

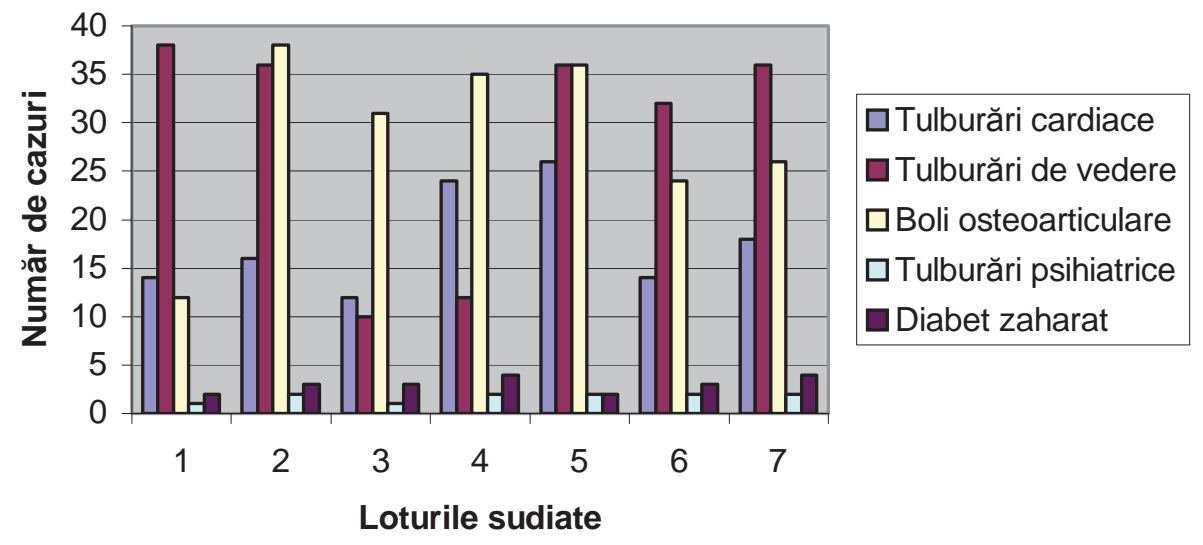

Fig. 2. Distribuția patologiei în loturile studiate

Modificările atenției distributive și concentrate corelate cu oboseala în muncă sunt ilustrate în tabelul II.

Tabel II. Modificările atenției distributive şi concentrate

\begin{tabular}{clcc}
\hline $\begin{array}{c}\text { Nr } \\
\text { crt }\end{array}$ & \multicolumn{1}{c}{ Lot } & $\begin{array}{c}\text { Aptitudini } \\
\text { slabe }\end{array}$ & $\begin{array}{c}\text { Aptitudini medii } \\
\text { și bune }\end{array}$ \\
\hline 1 & Muncă în condiții de izolare & 20 & 95 \\
2 & Muncă cu solicitare neurosenzorială & 9 & 99 \\
3 & Activitate cu efort fizic mediu/mare & 20 & 85 \\
4 & Activitate cu efort fizic mediu, dar expunere la intemperii & 24 & 86 \\
5 & Muncă de birou & 10 & 94 \\
6 & Activitate cu efort fizic mic (confecționeri fără expunere la zgomot) & 16 & 86 \\
7 & Activitate cu efort fizic mic (confecționeri cu expunere la zgomot) & 22 & 90 \\
\hline
\end{tabular}

Cel mai afectat lot în ceea ce privește alterarea atenției nu este conform așteptărilor lotul lucrătorilor cu suprasolicitare neurosenzorială, ci un lot cu activitate predominant fizică-lotul 4.

Dintre muncitorii cu activitate predominant fizică, cei la care există un cumul de noxe cu condiții excesive de temperatură și umiditate și cu o condiție socială mai modestă, au un procent mai ridicat de oboseală profesională, respectiv de alterare a atenției. De asemenea, zgomotul asociat cu condiția socială modestă la confecționeri, este factor de accelerare a oboselii profesionale.

Chiar dacă munca în condiții de izolare nu presupune efort fizic sau intelectual, condiția de muncă influențează stresul profesional, respectiv oboseala profesională.

Scăderea atenției la loturile studiate este ilustrată în figura 3. 


\section{Aptitudinea psihologică pe loturi}

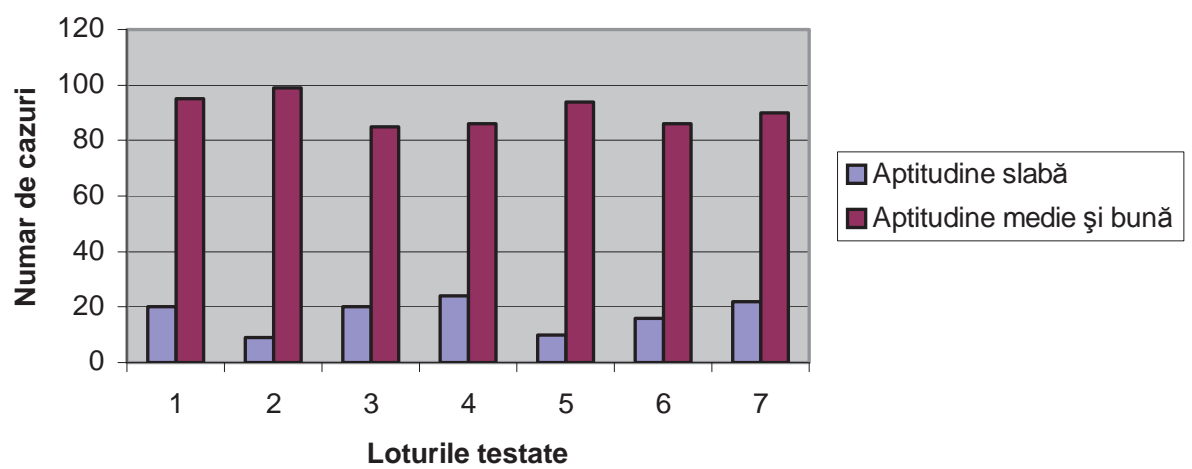

Fig. 3. Distribuția tulburărilor psihologice în loturile studiate

\section{Concluzii}

$\mathrm{Nu}$ există un paralelism între efortul fizic depus și apariția manifestărilor cardiace, psihice, osteoarticulare. Cumulul de noxe cum ar fi poziția nonergonomică, suprasolicitarea vizuală și neurosenzorială, stresul, contribuie la declanșarea unei patologii diverse.

La activitățile cu efort fizic, asocierea stresului psihosocial și a unor noxe fizice cum ar fi zgomotul, frigul, umezeala, au efecte mai pronunțate asupra sistemului osteoarticular și a celorlalte aparate și sisteme.

La profesiile care presupun muncă în cumul de noxe, pe lângă efortul fizic profesional, oboseala psihică se alătură tulburărilor de sănătate și oboselii fizice, reprezentând un factor principal de îmbolnăvire profesională și accidente de muncă.

\section{Referințe}

1. Petran, M. Manual de medicina muncii, Cluj Napoca, Editura Medicală Universitară "Iuliu Hațieganu", 2000.

2. Bogathy, Z. Manual de Psihologia muncii și organizațională, București, Editura Polirom, 2000. 